\title{
Impact of Accelerated Aging on the Performance Characteristics of "Green" Packaging Material of Polylactide
}

\author{
Krzysztof Moraczewski ${ }^{1 *}$, Alona Pawłowska', Tomasz Karasiewicz' ${ }^{1}$ Piotr Rytlewski \\ 1 Institute of Materials Engineering, Kazimierz Wielki University, ul. Chodkiewicza 30, 85-064 Bydgoszcz, Poland \\ *Corresponding author's e-mail: kmm@ukw.edu.pl
}

\begin{abstract}
The paper presents the result of the research on the impact of the accelerated aging process on selected operational properties of polylactide films containing natural antioxidants in the form of coffee, cocoa or cinnamon extracts. The research was focused on mechanical properties important for the packaging industry from the point of view of the reliability of the obtained products, i.e. tensile strength, relative deformation at maximum stress, relative deformation at break, Young's modulus, impact strength and storage module at various temperatures. The extracts have a positive effect on the determined mechanical properties. The obtained results were very often better not only than the values obtained for pure polymer, but also better than the values obtained for the film containing the synthetic anti-aging compound. It can therefore be concluded that the proposed plant extracts will have a positive effect on the stability of the mechanical properties of the manufactured products, which will allow long-term, reliable and safe operation of packaging. Proposed extracts can therefore be an alternative to the previously used synthetic anti-aging additives.
\end{abstract}

Keywords: polylactide, accelerated aging, mechanical properties

\section{INTRODUCTION}

"Green" materials are more and more popular among producers and consumers due to the combination of good quality products with conscious care for the environment. One of the reasons for promoting and encouraging producers and users to use "green materials" is the availability of raw materials needed for their production [18, 27, 29].

"Green" polymeric materials can be made using polymers derived from agricultural, forestry or marine raw materials $[2,3,14,17,28]$. These are abundant natural resources that are constantly replenished. Another beneficial property of "green" polymeric materials is their biodegradability, which makes them a natural material for use in such composting as sacks for collecting food or organic waste and for the production of packaging for food and other consumer products. But "green" polymeric materials must have adequate physical properties. Their properties should be controlled by technological means through the development of appropriate recipes and processing of polymer materials, ensuring, i.a. adequate resistance to aging.

Aging of materials is a common phenomenon occurring in all areas of life, in particular relating to technical facilities. The universality of this phenomenon means that more and more attention is paid to it in research, both from the point of view of understanding the mechanisms of the aging process and assessing its impact on the properties of materials $[6,16,19,26,30]$. The increase in the demand for polymer materials, materials that are often irreplaceable in the construction of machines, devices and products of everyday use - means that scientific and research work for years has been focused on explaining the complex mechanisms of the aging process, determining its impact on the properties - mainly physical and 
chemical - of plastics, as well as an assessment of the impact of processing conditions on the course of this phenomenon $[4,8,10,11,13]$.

Researchers around the world for many years have been conducting research to increase the stability of various polymers and to increase the resistance of these materials to atmospheric, chemical and thermal factors $[5,9,25]$. The most effective way to improve the stability of polymer materials is to use anti-aging compounds, i.e. special chemical compounds whose task is to increase the resistance of polymer materials to external factors such as heat at elevated temperatures, UV radiation or chemicals.

However, the nature of biodegradable polymers introduces certain requirements that should be set for chemical compounds to be used as anti-aging compounds. Such requirements include non-toxicity, low volatility, lack of volume migration and lack of negative effect on the composting process. An important feature should also be the possibility of use in packaging production, especially in products that have contact with food. This requirement results from the main application of biodegradable polymers today, mainly food packaging (food films, disposable tableware) [12, 20].

All these requirements are met by natural substances of plant origin. Not only would they not pollute the environment, but most importantly completely degrade without much problem. Rapid decomposition of proposed natural substances would not affect the decomposition time of the polymer matrix, and therefore of the entire product. That is why compounds of natural origin, easily available, which do not require special chemical synthesis processes and thus cheap are the in the recent years subject of numerous scientific studies in the scope of their potential use as anti-aging compounds. Among them, substances of plant origin containing natural polyphenols can be very promising due to their composition and chemical structure.

The paper presents the results of research on a "green" polylactide based polymer material containing extracts of coffee, cocoa and cinnamon which have height concentration of polyphenols. Detailed test results of selected processing, thermal and mechanical properties of samples containing different contents of tested extracts and the impact of the aging process on these properties are presented in [21].

However, the presented research focused on a more accurate analysis of the impact of the accelerated aging process on the mechanical and thermomechanical properties of the polymer films containing the optimal amount of individual extracts. The maintenance of good mechanical properties by the "green" polymer material throughout its lifetime is one of the key operating parameters that guarantees the correct and safe storage and operation of the protected product such as films and packaging for food or cosmetics.

\section{RESEARCH MATERIALS AND METHODOLOGY}

The matrix of tested materials was polylactide (PLA) 2003D (Cargill Down LLC, USA) with a density ( $\rho$ ) of $1.24 \mathrm{~g} / \mathrm{dm}^{3}$. According to the manufacturer, this polymer has a mass melt flow rate (MFR) of $6 \mathrm{~g} / 10 \mathrm{~min}\left(210^{\circ} \mathrm{C}, 2.16 \mathrm{~kg}\right)$. As anti-aging compounds, three natural compounds of plant origin were used: coffee extract, cocoa extract and cinnamon extract (Agrema Sp.z o.o., Poland). $0.5 \mathrm{wt} . \%$ of individual extract was added to the PLA matrix, obtaining materials marked as PK (coffee extract), PKK (cocoa extract) and PC (cinnamon extract). To assess the effectiveness of the proposed extracts, the properties of the given materials were compared with the reference sample (sample R), which contained 2 wt. $\%$ of butylated hydroxytoluene (BHT) (Sigma - Aldrich, USA). This compound is a commonly used synthetic anti-aging compound added to various polymers $[7,22,31]$. The results of $\mathrm{PK}, \mathrm{PKK}, \mathrm{PC}$ and $\mathrm{R}$ samples were also compared with results obtained for pure PLA (sample P) to get a full picture of the observed changes and the effect of anti-aging compounds on the properties of PLA.

The granulate of tested materials were obtained in the extrusion process using a twinscrew co-extruder BTSK 20 40D (Bühler, Germany). The temperature distribution in particular zones of the extruder and the head was: 170, $175,180,180$ and $180{ }^{\circ} \mathrm{C}$. After leaving the head, the material was cooled with an air stream and then granulated. Films were extruded from the obtained granulate in a subsequent processing. The single-screw extruder Plasti-Corder Lab Station (Brabender, Germany) was used in the production of films. The temperature distribution in particular zones of the extruder and the head were: 165,175 and $168{ }^{\circ} \mathrm{C}$. The film was obtained with a $170 \mathrm{~mm}$ flat gap head maintained at $158^{\circ} \mathrm{C}$. The thickness of the obtained film was 
approx. $0.5 \mathrm{~mm}$. From the obtained films, using a hydraulic press and appropriate dies, samples were cut in the form of paddles with dimensions according to [24] type 5 (Fig. 1).

The cut sample sets were subjected to an accelerated aging process. The aging process of the tested materials was carried out in a CCK 40/300NG climate chamber (Dycometal, Spain) at $45{ }^{\circ} \mathrm{C}, 70 \%$ relative humidity and UV radiation. The accelerated aging process was carried out for 1, 2 or 3 months. UV radiation was generated from 8 lamps (PHILIPS SUPER ACTINICA TL $60 \mathrm{~W} / 10-\mathrm{R}$ ISL) with a wavelength range from 350 to $400 \mathrm{~nm}$. The lamps were located directly above the samples so that the distance between them was as low as possible and the angle of incidence of radiation was $90^{\circ}$ to the surface of the samples.

Tensile parameters was determined using an Instron 3367 testing machine (Instron, USA) according to the $[23,24]$ standard. The extension rate was $50 \mathrm{~mm} / \mathrm{min}$. In the study tensile strength $\left(\sigma_{\mathrm{M}}\right)$, strain at maximum stress $\left(\varepsilon_{\mathrm{M}}\right)$, strain at break $\left(\varepsilon_{\mathrm{B}}\right)$ and Young's modulus (E) were determined. The value of selected parameters was determined for 12 samples. From the obtained results two extreme values were rejected and the final value was calculated as the arithmetic mean of 10 results.

The IMPats-15 hammer (ATS FAAR, Italy) was used in tensile-impact strength $\left(a_{\mathrm{tU}}\right)$ tests according to the [15] standard. The energy of the hammer was $4 \mathrm{~J}$ and the speed of the hammer at the moment of impact on was $2.9 \mathrm{~m} / \mathrm{s}$. The $\mathrm{a}_{\mathrm{tU}}$ value was determined for 12 samples. From the obtained results two extreme values were rejected and the final value was calculated as the arithmetic mean of 10 results.

The thermomechanical analyzer Q800 (TA Instruments, USA) was used to test the thermomechanical properties (DMA) according to the [1] standard. The tests were carried out in foil stretching mode with a frequency of 1 $\mathrm{Hz}$ with and a deformation amplitude of $15 \mu \mathrm{m}$. The samples were tested in the temperature range from 30 to $120^{\circ} \mathrm{C}$, with a heating rate of $3{ }^{\circ} \mathrm{C} /$ min. The research determined the storage modules $\left(E^{\circ}\right)$ of the tested materials at temperatures of 30,50 and $70{ }^{\circ} \mathrm{C}$ and the tangent of the $\delta$ angle $(\tan \delta)$, the so-called loss factor, based on which the glass transition temperature $\left(\mathrm{T}_{\mathrm{g}}\right)$ of individual materials was determined. The maximal peak of $\tan \delta$ was assumed as the $\mathrm{T}_{\mathrm{g}}$ value.

\section{RESULTS AND DISCUSSION}

\section{Tensile tests}

Tensile strength and susceptibility to deformation are important strength parameters of packaging materials in terms of their operational properties.

Considering first the impact of the additives used on the $\sigma_{M}$ of tested materials, it can be seen that the introduction of extracts to the PLA only slightly changed the $\sigma_{M}$ values (fig. 2).

The $\sigma_{\mathrm{M}}$ value of sample $\mathrm{P}$ was $62 \mathrm{MPa}$. The value obtained for the PK sample was practically the same as the P samples, while the PKK and PC samples were smaller by about $2 \mathrm{MPa}$. A much larger decrease in $\sigma_{\mathrm{M}}$ was observed after the reference anti-aging compound was added. The $\sigma_{\mathrm{M}}$ value of the R sample decreased by approx. $7 \mathrm{MPa}$ compared to the value of the P sample.

However, it was important to determine the influence of aging on the tensile strength of the materials. After the initial aging period, an increase in $\sigma_{\mathrm{M}}$ value was observed for all tested

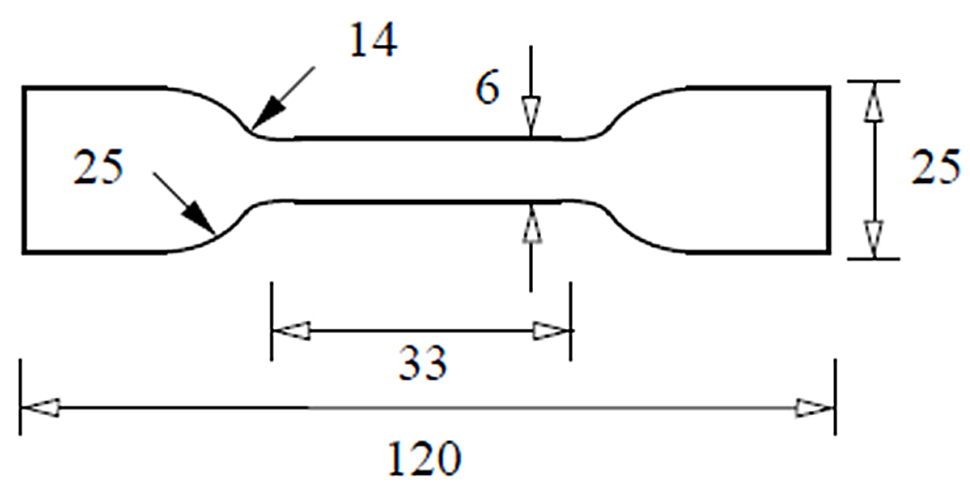

Fig. 1. Geometry of samples 


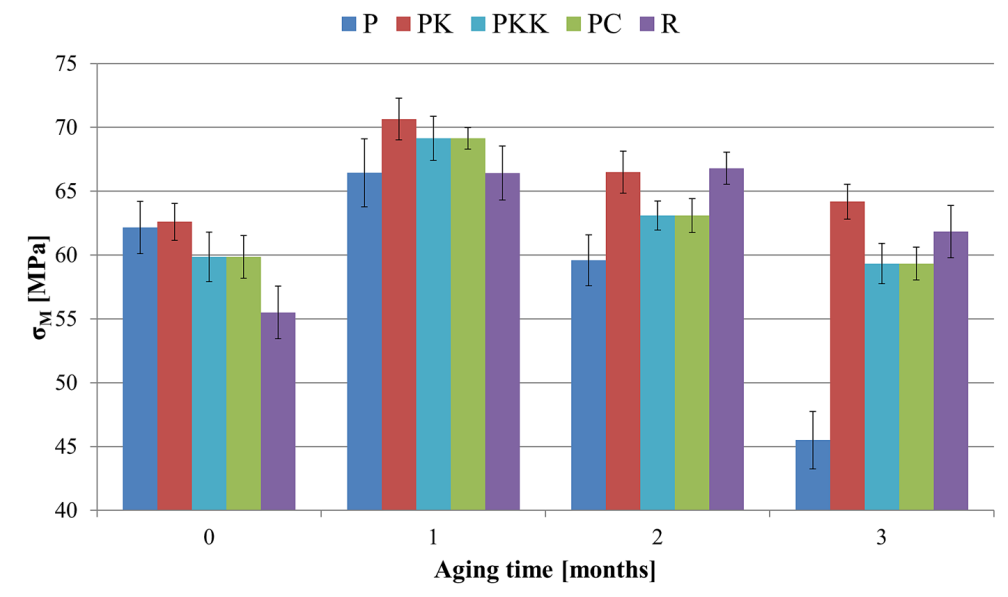

Fig. 2. Impact of aging time on tensile strength of tested materials; P - pure PLA; PK - coffee extract; PKK - cocoa extract; PC - cinnamon extract; R - reference sample 2\% BHT

materials. For sample P it was small - about 2 $\mathrm{MPa}$. However, it was significantly higher for samples containing anti-aging compounds. The $\sigma_{\mathrm{M}}$ value increased for PK, PKK, PC and R samples by approx. 8, 8, 10 and $11 \mathrm{MPa}$, respectively. The effect of the increase in tensile strength was probably due to the process of polymer macromolecular arrangement as a result of long exposition to elevated temperature, which results in improved mechanical properties. The large increases in $\sigma_{\mathrm{M}}$ for materials containing anti-aging compounds suggest that they have a positive effect on this process.

However, further aging of the materials led to a gradual deterioration of $\sigma_{\mathrm{M}}$. After 3 months of aging, the $\sigma_{\mathrm{M}}$ value of sample $\mathrm{P}$ decreased by approx. $21 \mathrm{MPa}$. The addition of anti-aging compounds inhibited the adverse effects of the accelerated aging process. The $\sigma_{M}$ value of the R sample decreased only by about $5 \mathrm{MPa}$. The proposed extracts were less effective. The $\sigma_{\mathrm{M}}$ values of PK, PKK and PC samples decreased by approximately 7, 8 and $10 \mathrm{MPa}$, respectively. The changes obtained were, however, definitely smaller than the changes observed for the pure polymer.

The introduction of extracts into PLA did not cause significant changes in $\varepsilon_{\mathrm{M}}$ and $\varepsilon_{\mathrm{B}}$. The results of materials containing coffee, cocoa or cinnamon extracts were very close to the results of pure PLA. Only in the case of sample containing reference anti-aging compund a greater drop of $\varepsilon_{\mathrm{B}}$ was observed (Fig. 3).

The aging of the tested materials only slightly influenced the $\varepsilon_{\mathrm{M}}$ values. Admittedly an increase in $\varepsilon_{\mathrm{M}}$ was observed after 1 month of aging, followed by a gradual decrease in this value, but the differences obtained were not significant and valuable conclusions cannot be clearly drawn.

Significant changes were however observed for $\varepsilon_{\mathrm{B}}$. Accelerated aging caused the largest changes in $\varepsilon_{\mathrm{B}}$ after 1 month of aging. After this period, the $\varepsilon_{\mathrm{B}}$ were definitely lower than the values of non-aged materials. The decrease in $\varepsilon_{\mathrm{B}}$ of all tested materials was similar - approx. 3\% for $\mathrm{PC}$ and R samples and approx. 5\% for P, PK and PKK samples. The longer aging period no longer caused further significant changes in the $\varepsilon_{\mathrm{B}}$. The $\varepsilon_{\mathrm{B}}$ values of the materials containing the extracts remained at the level obtained for the $\mathrm{P}$ sample. Just for the R sample a further decrease of $\varepsilon_{\mathrm{B}}$ by extra $2 \%$ was observed in compared with material after 1 month of aging.

The influence of the aging process on the Young's modulus of the tested materials was also analyzed (Fig. 4).

The $\mathrm{E}$ value of the unaged sample $\mathrm{P}$ was about $1640 \mathrm{MPa}$ and did not change significantly after the addition of the extracts. Larger changes were observed after introducing the reference anti-aging compound into the matrix. The E value of sample R decreased by approx. $140 \mathrm{MPa}$ reaching $1500 \mathrm{MPa}$.

Up to 2 months of aging, this process did not cause significant $\mathrm{E}$ changes in most of the tested materials. Apart from the materials with cinnamon extract and reference anti-aging compound, the difference in $\mathrm{E}$ value did not exceed $60 \mathrm{MPa}$. For PC and R samples, E values increased by approx. 130 and $170 \mathrm{MPa}$, respectively. However, large changes were observed after 3 months of aging. For all samples there was a large increase in the $\mathrm{E}$ value after the level of about $1800 \mathrm{MPa}$. 
a)
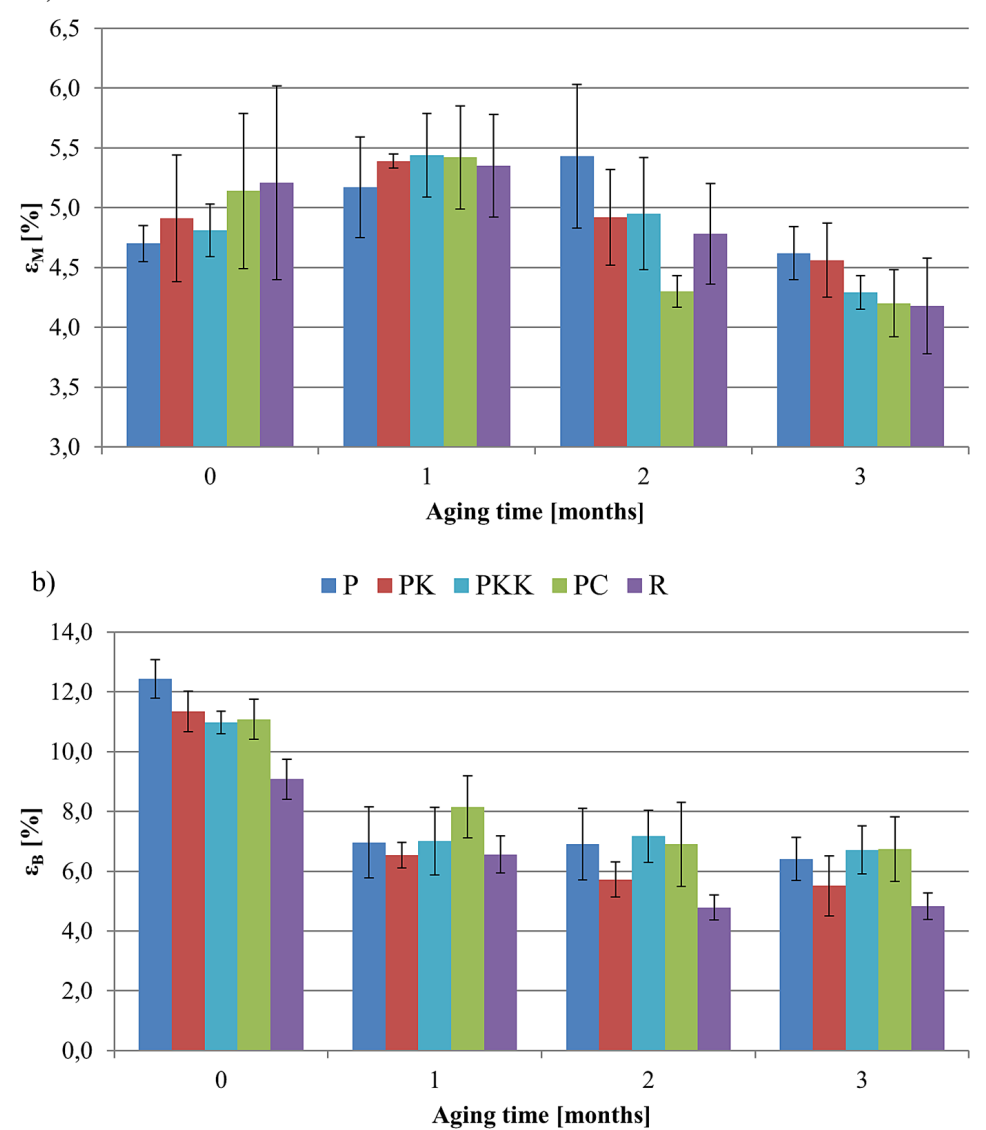

Fig. 3. Impact of aging time on a) strain at maximum stress $\left(\varepsilon_{\mathrm{M}}\right)$, b) strain at break $\left(\varepsilon_{\mathrm{B}}\right)$ of tested materials; $\mathrm{P}-$ pure PLA; PK - coffee extract; PKK - cocoa extract; PC - cinnamon extract; R - reference sample 2 wt. $\%$ BHT

Therefore, studies show that the extracts, unlike the reference anti-aging compound, should not only provide good tensile strength of products during operation, but also not adversely affect the ability to deform these materials.

\section{Tensile - impact strength}

Elements of packaging products are exposed to dynamic loads during use. For this reason, it is necessary to know the properties that characterize the behavior of the material in the event of sudden load changes. Impact resistance is therefore one of the key parameters determining the operational properties of packaging materials.

The $a_{\mathrm{tU}}$ value of sample $P$ was $140 \mathrm{~kJ} / \mathrm{m}^{2}$ (Fig. 5). Of the extracts used, only cinnamon extract caused a decrease in impact strength. The $\mathrm{a}_{\mathrm{tU}}$ value of the PC sample decreased by approx. $12 \mathrm{~kJ} / \mathrm{m}^{2}$ in relation to the $P$ sample. The impact strength of the materials containing the other two extracts was at the same level as that of the pure polymer. In turn, the reference antiaging compound increased the impact strength of the material. The $\mathrm{a}_{\mathrm{tU}}$ value of the $\mathrm{R}$ sample increased by approx. $5 \mathrm{~kJ} / \mathrm{m}^{2}$ compared to the value of the P sample.

Also for impact strength, accelerated aging initially resulted in an increase in the $a_{t U}$ value of the tested materials, which could be due to the arrangement of macromolecules. The $a_{t U}$ value of sample P increased by $10 \mathrm{~kJ} / \mathrm{m}^{2}$ after 1 month of aging. The magnitude of growth in materials depended on the type of extract. The smallest increase of $5 \mathrm{~kJ} / \mathrm{m}^{2}$ was observed for coffee extract. Much larger changes were observed for cocoa and cinnamon extracts, where the increase in $\mathrm{a}_{\mathrm{tU}}$ value was 14 and $17 \mathrm{~kJ} / \mathrm{m}^{2}$, respectively. An increase at a similar level was observed for sample with reference compound where the $\mathrm{a}_{\mathrm{tU}}$ value increased by $12 \mathrm{~kJ} / \mathrm{m}^{2}$.

As a result of progressing aging the impact strength of the tested materials decreased. The largest decrease in $\mathrm{a}_{\mathrm{tU}}$ was observed for pure polymer. The $a_{t U}$ value of the P sample after 3 months of aging decreased by approx. $28 \mathrm{~kJ} / \mathrm{m}^{2}$ relative to the non-aged sample. The proposed extracts inhibited the adverse effects of external factors 


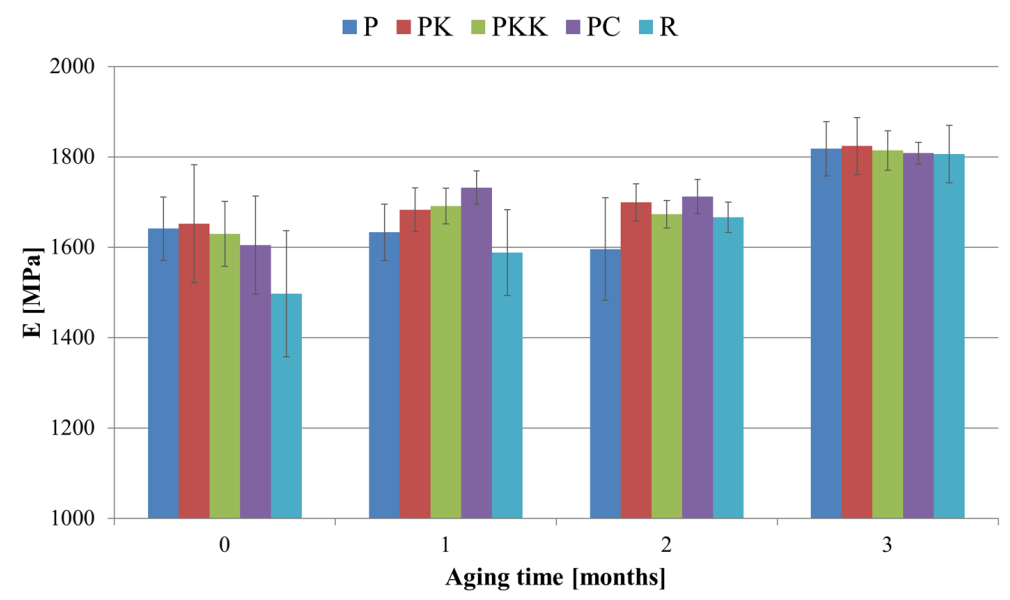

Fig. 4. Impact of aging time on the Young's modulus (E) of tested materials, P - pure PLA; PK - coffee extract; PKK - cocoa extract; PC - cinnamon extract; R - reference sample 2 wt.\% BHT

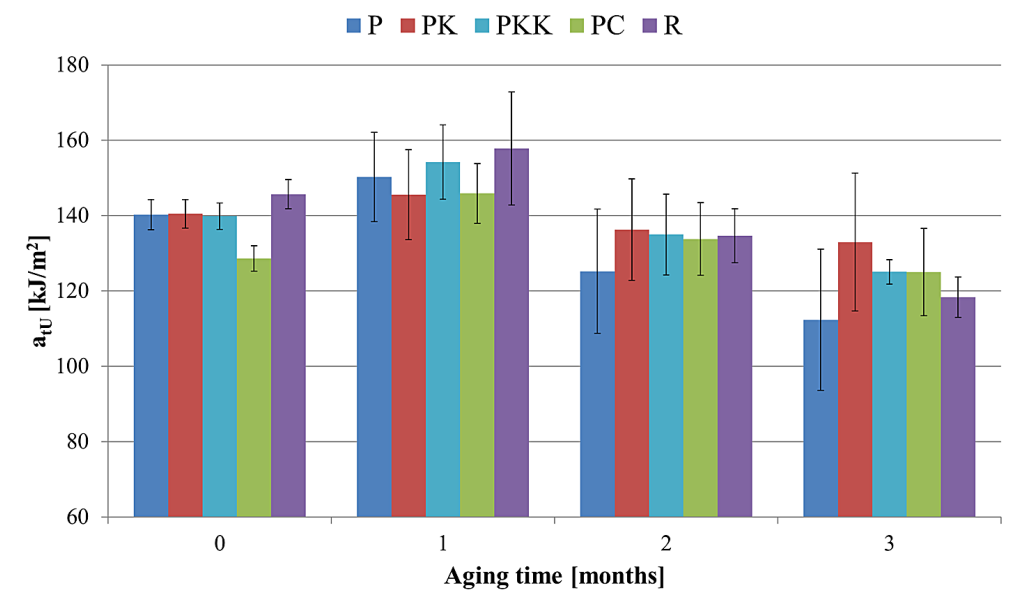

Fig. 5. Impact of aging time on tensile-impact strength of tested materials; P - pure PLA; PK - coffee extract; PKK - cocoa extract; PC - cinnamon extract; R - reference sample 2 wt.\% BHT

occurring during accelerated aging limiting the decrease in impact strength of the obtained materials. Cinnamon extract turned out to be the most effective. The $\mathrm{a}_{\mathrm{tU}}$ value of the PC sample only decreased by approx. $4 \mathrm{~kJ} / \mathrm{m}^{2}$ relative to the nonaged sample. A larger drop was observed for the PK sample, where the difference in $\mathrm{a}_{\mathrm{t} U}$ between the aged and non-aged sample was about $8 \mathrm{~kJ} / \mathrm{m}^{2}$. An even greater difference of about $15 \mathrm{~kJ} / \mathrm{m}^{2}$ was recorded for the PKK sample.

Importantly, the effectiveness of the extracts in inhibiting the decrease in impact resistance proved to be greater than the effectiveness of the reference compound. Although the final $\mathrm{a}_{\mathrm{tU}}$ value of the R sample was about $6 \mathrm{~kJ} / \mathrm{m}^{2}$ higher than the value obtained for the $\mathrm{P}$ sample, the total decrease in value was about $27 \mathrm{~kJ} / \mathrm{m}^{2}$, i.e. it was practically the same as the decrease observed for the P sample.

\section{Thermomechanical analysis}

Due to the wide range of applications of packaging materials and the resulting fact of using these materials to produce various types of packaging, it is important to know the operational properties at different temperatures. Packaging is often used or stored at elevated temperatures. Therefore, it is important to include learning about their mechanical properties at higher temperatures.

The value of the storage modulus at $30{ }^{\circ} \mathrm{C}$ $\left(\mathrm{E}_{30}{ }_{30}\right.$ ) of sample $\mathrm{P}$ was about $2700 \mathrm{MPa}$ (Fig. 6). $\mathrm{E}_{30}{ }_{30}$ values increased after adding the extracts. The E' ${ }_{30}$ values of PK, PKK and PC samples were higher by approx. 275, 450 and $615 \mathrm{MPa}$, respectively. The highest increase of approx. 810 MPa was however recorded for sample R. The increase is $\mathrm{E}_{30}{ }_{30}$ is probably the result of an increase in the stiffness of materials after introducing the 

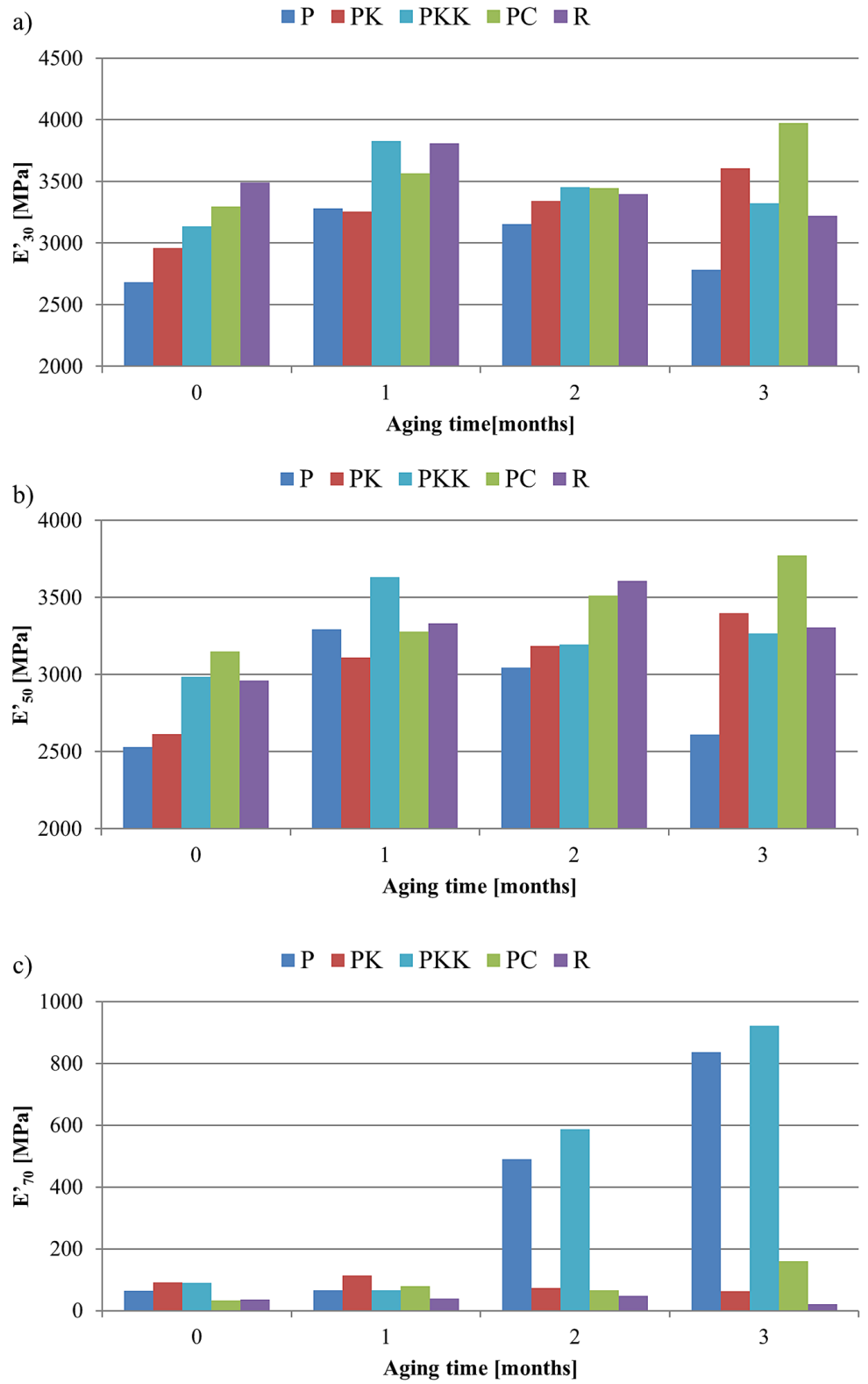

Fig. 6. Impact of aging time on the storage modulus of tested materials determined at a) $30{ }^{\circ} \mathrm{C}$, b) $50{ }^{\circ} \mathrm{C}$ and c) $70{ }^{\circ} \mathrm{C}$; P - pure PLA; PK - coffee extract; PKK - cocoa extract; PC - cinnamon extract; R - reference sample 2 wt.\% BHT

powder filler matrix and a slight increase in the degree of crystallinity, which was confirmed by other studies.

As with the other mechanical properties described earlier, E' ${ }_{30}$ also increases after the initial period of aging. The increase in the arrangement of macromolecules is probably also accompanied by an increase in the stiffness of the materials, which is indirectly confirmed by the decreasing deformation values of these materials. The value of $\mathrm{E}_{30}$ of sample $\mathrm{P}$ increased by about $600 \mathrm{MPa}$ compared to an unaged sample. A similar increase was also observed for the PKK sample. Much smaller differences of approx.
$300 \mathrm{MPa}$ were obtained for PK and PC samples as well as R samples.

The course of further $\mathrm{E}_{30}$ changes along with the progressing aging time, however, depended on the tested material. A gradual decrease in $\mathrm{E}_{30}$ was observed for sample P. After 3 months of aging, the value of $\mathrm{E}_{30}$ decreased by about $500 \mathrm{MPa}$ relative to the sample after the shortest aging period, reaching a value close to the value of the non-aged sample. A similar course of changes occurred for the PKK sample. The difference $\mathrm{E}_{30}$ between a sample aged for 3 months and a sample aged for 1 month was about $510 \mathrm{MP}$, and the final value was close to the value obtained for the 
unaged sample. It should be noted, however, that despite the similar nature of the observed changes, the material containing cocoa extract was characterized by much higher $\mathrm{E}_{30}$ values. The differences between these materials reached 550 $\mathrm{MPa}$. The reduction of $\mathrm{E}_{30}$, was also observed for sample R. The value of $\mathrm{E}_{30}{ }_{30}$ decreased by about $180 \mathrm{MPa}$ compared to the value obtained after 1 month of aging. On the other hand, for PK and PC samples, an increase in the $\mathrm{E}_{30}{ }_{30}$ value was observed along with an increase in aging time. Compared to the samples aged by 1 month, the values of $E_{30}$ of these samples were higher by about 350 and $410 \mathrm{MPa}$, respectively.

The course of changes in $\mathrm{E}_{50}$ values of both non-aged samples and samples subjected to aging was very similar to the changes observed for $\mathrm{E}_{30}$. The most important difference was the smaller $\mathrm{E}_{50}$, values of analogous samples resulting from the changing material characteristics at higher temperatures. As the measurement temperature approaches the glass transition temperature of the tested material, the value of the conservative module decreases, which is associated with the increase in the possibility of movement of polymer chains.

The increase in material temperature resulted in a further and very large decrease in the storage modulus for both non-aged and aged samples. The E' ${ }_{70}$ values of most samples ranged from 30 to $160 \mathrm{MPa}$. Exceptions were samples $\mathrm{P}$ and PKK, which after 2 and 3 months of aging were characterized by high $\mathrm{E}_{70}$ values. The large decrease in the behavioral modulus of most materials was caused by the proximity of the glass transition temperature $\left(\mathrm{T}_{\mathrm{g}}\right)$, which was between 71 and 72.5 ${ }^{\circ} \mathrm{C}$ depending on the material (Fig. 7). Only P and PK samples were characterized by higher $\mathrm{T}_{\mathrm{g}}$ values of about $74^{\circ} \mathrm{C}$. Since the change in the storage modulus within the glass transition is very rapid, a shift of only $2{ }^{\circ} \mathrm{C}$ in $\mathrm{T}_{\mathrm{g}}$ is enough for the resulting $\mathrm{E}_{70}{ }_{70}$ values to be significantly higher than those obtained for the other samples.

\section{CONCLUSIONS}

The paper presents the result of studies on the impact of the accelerated aging process on selected operational properties of polylactide films containing natural antioxidants in the form of coffee, cocoa or cinnamon extracts, and the results were compared with the results of pure polylactide film and a film containing synthetic antioxidant.

It was found that the extracts used favorably affect the stability of the determined mechanical properties as a function of aging time. The extracts limited the decrease in tensile strength and tensile-impact strength observed for the material made of pure polylactide. The tensile strength of pure polylactide after the aging process was lower by $27 \%$ than the initial sample, while the values of the samples containing the tested extracts were similar to starting values. The tensile-impact strength after aging of pure polylactide decreased by $20 \%$. For extracts, the decrease was smaller and ranged from $3 \%$ for cinnamon extract to $10 \%$ for cocoa extract.

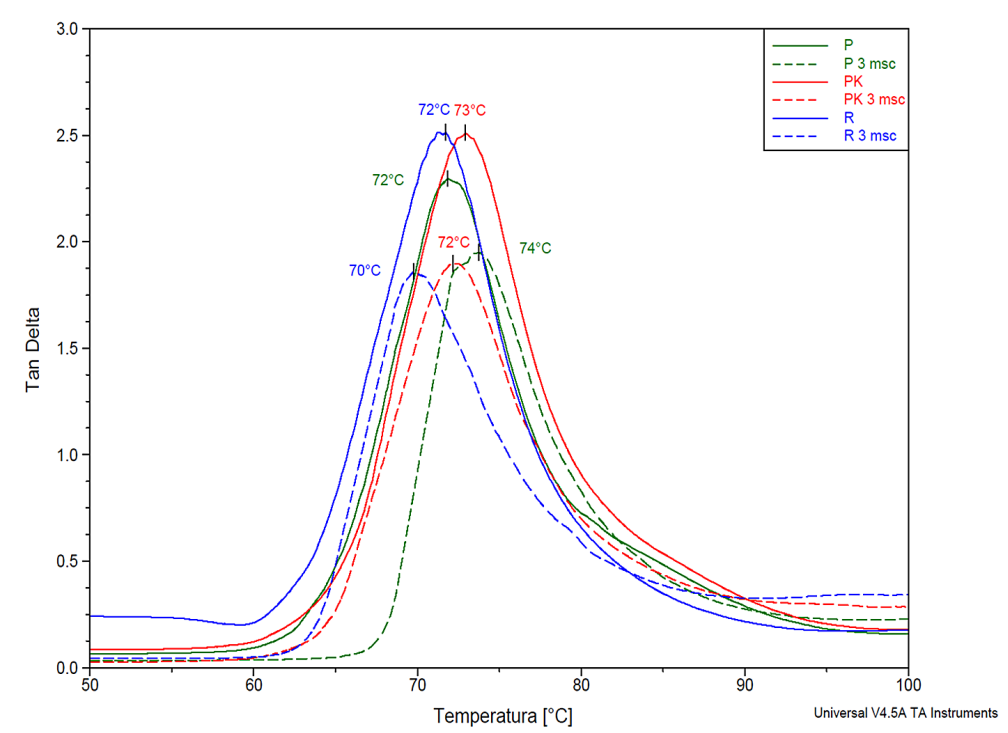

Fig. 7. Glass transition temperatures of selected samples; $\mathrm{P}$ - pure PLA; PK - coffee extract; $\mathrm{R}$ - reference sample 2\% BHT 
The aging only slightly influenced the strain at maximum stress of materials and the differences obtained were not significant. The strain at break of materials was more prone to accelerated aging however, the decrease in all tested samples was similar - approx. 3\% for materials with cinnamon extract or reference anti-aging compound and approx. 5\% for pure polylactide, coffee and cocoa extracts.

The storage modulus of pure polylactide, determined at 30 and $50^{\circ} \mathrm{C}$, increased by 18 and $3 \%$, respectively after aging. The cocoa extract had the most positive effect on the stability of the storage modulus determined at different temperatures. The storage modulus at 30 and $50^{\circ} \mathrm{C}$ of samples containing cocoa extract only increased by 10 and $9 \%$, respectively. In the case of the remaining extracts, the changes were more significant and reached $30 \%$ of the initial value (coffee extract).

The obtained results were very often better not only than the values obtained for pure polymer, but also better than the values obtained for the film containing the synthetic anti-aging compound. Studies showed that the proposed plant extracts have a positive effect on the stability of the mechanical properties of the products manufactured from them, which will allow long-term, reliable and safe operation of packaging. the products manufactured with their help. Despite the fact that the presented materials were developed mainly with the packaging industry in mind, thanks to their properties and good resistance to aging processes, they can also be used in other industries, such as automotive, furniture or construction industries.

\section{Acknowledgement:}

The studies have been financed by the National Science Centre upon project 2015/17/D/ ST8/02618.

\section{REFERENCES}

1. ASTM D 4065 06, 2006, Standard Practice for Plastics: Dynamic Mechanical Properties: Determination and Report of Procedures.

2. Atli A, Candelier K, Alteyrac J. Mechanical, thermal and biodegradable properties of bioplastspruce green wood polymer composites. International Journal of Chemical, Molecular, Nuclear, Materials and Metallurgical Engineering 2018; 12(5): 226-238.
3. Baishya P, Saikia D, Mandal M. \& Maji, T.K. Biodegradability, flammability, dimensional stability, and UV resistance study of green wood starch gluten nanocomposites. Polymer Composites 2019; 40: 46-55.

4. Barczewski M., Andrzejewski J., Matykiewicz D., Krygier A., Kloziński A Influence of accelerated weathering on mechanical and thermomechanical properties of poly(lactic acid) composites with natural waste filler. Polimery 2014; 64(2): 119-126.

5. Brzozowska A., Rabiej S., Fabia J., Nowak J. Changes in thermal properties of isotactic polypropylene with different additives during aging process. Polimery 2014; 59: 302-307.

6. Brzozowska-Stanuch A, Rabiej S, Sarna E, Maślanka M. Wpływ promieniowania UV na właściwości poliamidu PA6 - metody starzenia materiałów polimerowych. Polimery i kompozyty konstrukcyjne. Cieszyn: Logos Press, 2010; 48-57.

7. Byun Y, Kim Y.T, Whiteside S. Characterization of an antioxidant polylactic acid (PLA) film prepared with $\alpha$-tocopherol, BHT and polyethylene glycol using film cast extruder. Journal of Food Engineering 2010; 100(2): 239-244.

8. Carrasco F, Pages P, Pascual S, Colom X. Artificial aging of high-density polyethylene by ultraviolet irradiation. European Polymer Journal 2001; 37(7): 1457-1464.

9. Drogoń A., Skotnicki M., Pyda M. Physical aging of polylactide-valsartan system investigated by differential scanning calorimetry. Polimery 2020; 65(7-8): 533-541.

10. Gates T.S, Grayson M.A. On the use of accelerated aging methods for screening high temperature polymeric composite materials. American Institute of Aeronautics and Astronautics 1999; 925-935.

11. Głogowska K., Majewski Ł., Garbacz T., TorŚwiątek A. The effect of ageing on selected properties of polylactide modified with blowing agents. Advances in Science and Technology Research Journal 2019; 13(4): 204-213.

12. Gołębiewski J, Gibas E, Malinowski R. Wybrane polimery biodegradowalne - otrzymywanie, właściwości, zastosowanie. Polimery 2008; 53(11-12): 799-807.

13. Hutchinson J.M, Physical aging of polymers. Progress in Polymer Science 1995; 20: 703-760.

14. Islam M.N, Dungani R, Khalil H.A, Alwani M.S, Nadirah W.W. \& Fizree H.M. Natural weathering studies of oil palm trunk lumber (OPTL) green polymer composites enhanced with oil palm shell (OPS) nanoparticles. SpringerPlus 2013; 2(1): 592.

15. ISO 8256:2004, Plastics - Determination of tensile-impact strength.

16. Jachowicz T., Garbacz T., Tor-Świątek A., Gajdoš 
I., Czulak A. Investigation of selected properties of injection-molded parts subjected to natural aging. International Journal of Polymer Analysis and Characterization 2015; 20(4): 307-315.

17. Jadhav A.C, Pandit P, Gayatri T.N, Chavan P.P, Jadhav N.C. Production of Green Composites from Various Sustainable Raw Materials. Green Composites. Textile Science and Clothing Technology. Springer Nature Singapore 2019.

18. La Mantia F.P, Morreale M. Green composites: A brief review. Composites Part A: Applied Science and Manufacturing 2011; 42(6): 579-588.

19. Lenartowicz M., Swinarew B., Swinarew A., Rymarz G. The evaluation of long-term aged PVC, International Journal of Polymer Analysis and Characterization. 2014; 19(7): 611-624

20. Lim L.T, Auras R, Rubino M. Processing technologies for poly(lactic acid). Progress in Polymer Science 2008; 33(8): 820-852.

21. Moraczewski K., Stepczyńska M., Malinowski R., Karasiewicz T., Jagodziński B., Rytlewski P. The Effect of Accelerated Aging on Polylactide Containing Plant Extracts. Polymers 2019, 11(4): 575.

22. Ortiz-Vazquez H, Shin J, Soto-Valdez H, Auras R. Release of butylated hydroxytoluene (BHT) from Poly(lactic acid) films. Polymer Testing 2011; 30(5): 463-471.

23. PN-EN ISO 527-3:1998, Plastics - Determination of tensile properties - Part 1: General principles.

24. PN-EN ISO 527-3:1998, Plastics - Determination of tensile properties - Part 3: Test conditions for films and sheets.
25. Richert A. Biodegradowalne polimery pochodzenia naturalnego $\mathrm{z}$ surowców odnawialnych. Polimery biodegradowalne. Zagadnienia wybrane. Toruń: Instytut Inżynierii Materiałów Polimerowych i Barwników, 2013; 21-48.

26. Tavares A.C, Gulmine J.V, Lepienski C.M, Akcelrud L. The effect of accelerated aging on the surface mechanical properties of polyethylene. Polymer Degradation and Stability 2003; 81(2): 367-373.

27. Thakur V.K, Singha A.S. \& Mehta I.K. Renewable Resource-Based Green Polymer Composites: Analysis and Characterization. International Journal of Polymer Analysis and Characterization 2010; 15(3): 137-146.

28. Thakur V.K, Singha A.S. \& Thakur M.K. Green Composites from Natural Fibers: Mechanical and Chemical Aging Properties. International Journal of Polymer Analysis and Characterization 2012; 17(6): 401-407.

29. Thakur V.K, Thakur M. K, Raghavan P, Kessler M.R. Progress in Green Polymer Composites from Lignin for Multifunctional Applications: A Review. ACS Sustainable Chemistry \& Engineering 2014; 2(5): 1072-1092.

30. Tiganis B.E, Burn L.S, Davis P, Hill A.J. Thermal degradation of acrylonitrile butadiene-styrene (ABS) blends. Polymer Degradation and Stability 2002; 76(3): 425-434.

31. Xia Y, Rubino M. Effect of cut edge area on the migration of BHT from polypropylene film into a food simulant. Polymer Testing 2016; 51: 190-194. 